\title{
Inaccuracies in weather data and their effects on crop growth simulation results. II. Water-limited production
}

\author{
Sanderine Nonhebel
}

Department of Theoretical Production Ecology, Agricultural University, PO Box 430, 6700 AK Wageningen, The Netherlands

\begin{abstract}
In weather data sets used by crop modellers irregularities occur as inaccuracies in given data and as missing values. The effects of irregularities in temperature and global radiation data on potential production of spring wheat are discussed in a companion paper (Nonhebel 1994; Clim. Res. 4 47-60). Here the effects of irregularities in weather data on simulated water-limited production of spring wheat are examined, using the same methods as described previously. In general, the crop growth model used was not sensitive to inaccuracies in vapour pressure data and wind speed and average data for these variables could be used to replace missing values. The sensitivity of the model to inaccuracies in other weather data depended on the amount of water available to the crop. In dry years the model was sensitive to inaccuracies in precipitation and radiation data but less so to inaccuracies in air temperature. When water was not limiting the model was not sensitive to inaccuracies in precipitation, but was sensitive to inaccuracies in temperature and radiation data. Use of average values for temperature and global radiation led to large deviations in simulation results. For all variables except precipitation, data from a nearby weather station represented good estimates for missing values. Rainfall data for estimations should be obtained from a site in the immediate vicinity. However, when the complete data set (i.e. for all weather variables) from a station $40 \mathrm{~km}$ away was used as input for the model, deviations of up to $2 \mathrm{tha}^{-1}(=30 \%)$ in simulated yields were found.
\end{abstract}

KEY WORDS: Weather data $\cdot$ Crop-growth simulation models $\cdot$ Water-limited production

\section{INTRODUCTION}

Weather data are important input variables in crop growth simulation models, and simulation results are largely determined by these input data. Therefore, it is important to analyse both the errors that can occur in weather data and the effect of these errors on simulation results. In the companion paper (Nonhebel 1994a) inaccuracies in air temperature and global radiation data were estimated and their effects on simulated potential production were discussed; it was shown that inaccuracies in weather data can have large effects on the simulation results. However, crops hardly ever reach their potential production level, since some water shortage usually occurs during the growing season. Therefore, it is logical to analyse the effects of inaccuracies in weather data on simulated waterlimited production as well.
Daily data on maximum and minimum air temperature, global radiation, precipitation, vapour pressure and wind speed are required for simulation of waterlimited production. Basically, air temperature and global radiation determine the potential production, and precipitation determines the extent to which this production is actually reached.

One of the characteristics of precipitation is its highly irregular distribution in space and time. In De Bilt, The Netherlands (Fig. 1 in Nonhebel 1994a) annual precipitation varied from less than $400 \mathrm{~mm}$ (1921) to more than $1100 \mathrm{~mm}$ (1965) (Buishand \& Velds 1980). This implies that the degree of the water deficit varies from one year to another. It is to be expected that differences in water deficit will affect the sensitivity of the simulation model to inaccuracies in certain weather data. Vapour pressure and wind speed, for instance, are used only to calculate evapotranspiration. When 
enough water is available, errors in evapotranspiration are not likely to affect the final yield. In dry years, on the other hand, accurate calculation of evapotranspiration is vital for good simulation of crop production. Thus, the sensitivity of the model to inaccuracies in weather variables will differ from year to year. The effects in dry and wet years must therefore be distinguished.

At the potential production level, good vegetative growth is essential for a high yield (Nonhebel 1994a). The effects of temperature and global radiation on simulated potential yield can be explained by their effects on growth during the vegetative period. However, this is not the case in a water-limited situation. A high level of dry matter production during vegetative growth implies that a large amount of water is used during this period. In the worst case, all the water is used up before grain filling starts, so that no grain yield is obtained at all. Thus, to achieve high yields, dry matter production in the vegetative period and the amount of water available during the grain filling period must be balanced.

In this paper the effect of inaccuracies in temperature and global radiation, as estimated in Nonhebel (1994a), is examined for water-limited production. In addition, inaccuracies in precipitation, vapour pressure and wind speed data are estimated and their effects on simulation results determined. For each weather variable the effect of using averages was determined, as well as the effect of using data from a nearby station. The results are discussed for each weather variable separately Finally, the combined effect of random inaccuracies in all weather data variables on simulation results is examined, as well as the effect of using all data from another station.

\section{METHODS}

The crop growth simulation model used in the companion paper (Nonhebel 1994a) was extended with an evapotranspiration routine and a soil water balance. Potential soil evaporation and crop transpiration were simulated according to the Big Leaf model (PenmanMonteith equation; Monteith 1965), and a soil water balance based on van Keulen \& Seligman (1987) was used. The soil is treated as a multi-layered system with 10 layers. When precipitation occurs, the first layer is filled up to field capacity and all excess water entering the layer drains to the next layers. Soil moisture losses occur by drainage below the potential rooting zone, by crop transpiration and by soil evaporation. When water shortage occurs, the assimilation rate is reduced proportionally to the ratio between actual transpiration (which depends on the available amount of water) and potential transpiration (de Wit 1958). Other processes are not affected by water shortage.

Here, the soil profile was regarded as homogeneous and physical parameters of a hypothetical soil with a low water holding capacity were used $\left(200 \mathrm{~mm} \mathrm{~m}^{-1}\right)$; depths of successive soil layers were set at $2,8,10,10$, $10,10,10,10,10$ and $20 \mathrm{~cm}$, and on sowing the whole profile was at field capacity.

With respect to the effect of inaccuracies, use of averages and use of data from another station, the same methods as described in Nonhebel (1994a) were used.

When crop production was simulated with the original weather data set (Wageningen, 1954 to 1987), severe water shortage occurred in only 5 years (1957, $1959,1973,1976,1986)$, resulting in yields of 2 to $5 \mathrm{t}$ $\mathrm{ha}^{-1}$. In all other years water shortage was much less severe and yields were higher.

\section{AIR TEMPERATURE}

\section{Introduction}

Air temperature affects simulated water-limited production in 2 ways: first, it determines timing and duration of the crop growing period, and second, it is used to calculate the vapour pressure deficit of the air. The effects of inaccuracies in temperature data on duration and timing of the growing period are discussed extensively in Nonhebel (1994a). When periods with unfavourable weather conditions occur during the growing season, correct temperature data are essential, since temperature determines whether or not these periods occur during the sensitive period of growth. For water-limited production, correct timing of the growing period is even more important than for potential production. Precipitation is distributed irregularly over the year, so a shift in the growing period can have large consequences for the amount of precipitation occurring within this period.

In the model, daily vapour pressure deficit of the air (VPD) is determined from the saturated vapour pressure (SVP) at the average daily temperature $[T=0.5 \times$ $\left.\left(T_{\min }+T_{\max }\right)\right]$ and the recorded vapour pressure (VAP) (Goudriaan 1977):

$$
\begin{aligned}
& S V P=6.11 \mathrm{e}^{\frac{17.4 T}{7+239}} \\
& V P D=S V P-V A P
\end{aligned}
$$

When temperature is overestimated, saturated vapour pressure is overestimated, as is the vapour pressure deficit. At $15^{\circ} \mathrm{C}$, overestimation of tempera- 
ture by $1^{\circ} \mathrm{C}$ results in an overestimation of vapour pressure deficit by about $1.0 \mathrm{mb}$.

\section{Results}

In most years underestimation of air temperature resulted in overestimation of yield (grains, dry matter) and overestimation of air temperature resulted in underestimation of yield (Fig. 1). In comparison with the potential yield (Fig. 4 in Nonhebel 1994a), fewer years occurred in which an opposite effect was achieved (i.e. underestimation of temperature resulting in underestimation of yield). In some years inaccuracies of $1^{\circ} \mathrm{C}$ in temperature data resulted in a deviation in the amount of precipitation received during crop growth of over $50 \mathrm{~mm}$ (deviation of 15 to $30 \%$, due to shift of the growing season), but in most years this amount was not affected.

Use of average values over $10 \mathrm{~d}$ resulted in a good simulation of the yield, although in some years a deviation of nearly $1 \mathrm{t} \mathrm{ha}^{-1}$ was obtained (Fig. 2). Use of monthly averages led to a larger deviation in simulated yield, and when climatic averages were used, yields in low-yield years were overestimated and yields in highyield years were underestimated (Fig. 2). Using temperature data from De Bilt resulted in a deviation in simulated yield of the same order of magnitude as that produced by use of $10 \mathrm{~d}$ averages (Fig. 3). Using data from De Kooy led to an overestimation of the simulated yield of 0.5 to $1.0 \mathrm{t} \mathrm{ha}^{-1}$ in nearly all years (Fig. 3 ).

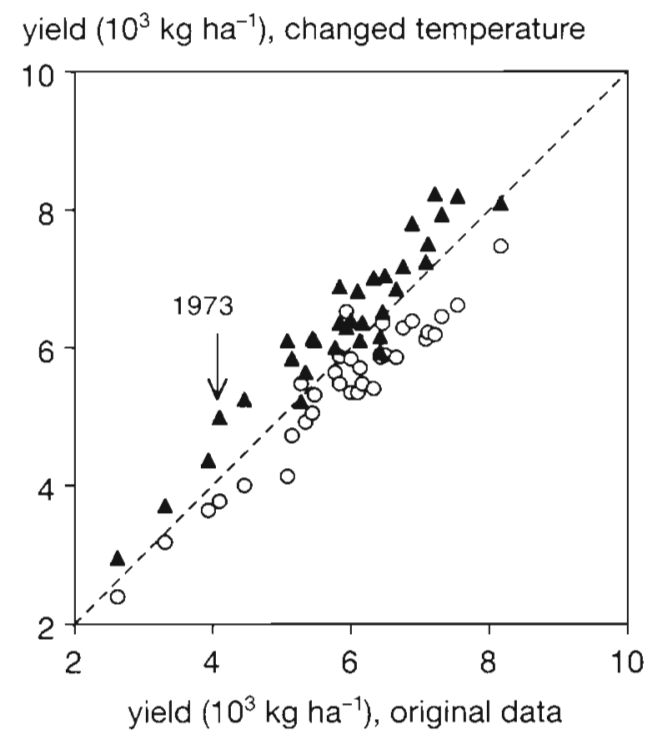

Fig. 1. Comparison between water-limited spring wheat yield simulated with the original weather data set (Wageningen, 1954 to 1987 ) and simulated yield when daily minimum and maximum air temperatures in this set were increased (O) or decreased $(\mathbf{\Delta})$ by $1{ }^{\circ} \mathrm{C}$ yield $\left(10^{3} \mathrm{~kg} \mathrm{ha}^{-1}\right)$, average temperature

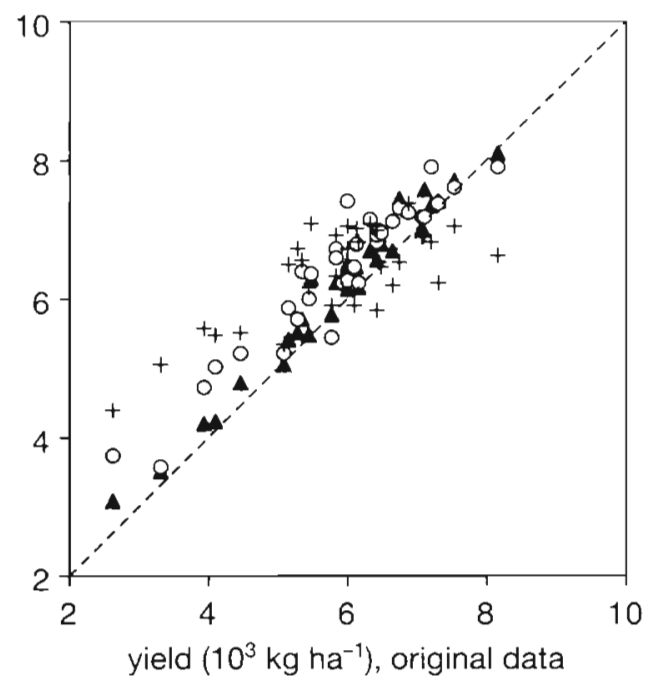

Fig. 2. Comparison between simulated water-limited spring wheat yield using daily weather data from the original data set (Wageningen, 1954 to 1987) and simulated yield when daily values for air temperature were estimated from average values: (\$) $10 \mathrm{~d},(0)$ monthly averages, $(+)$ climatic averages

\section{Discussion}

The combination of the effects of temperature on potential production, on crop water requirements and on the amount of water available (through timing of

$$
\text { yield }\left(10^{3} \mathrm{~kg} \mathrm{ha}^{-1}\right) \text {, temp. from other station }
$$

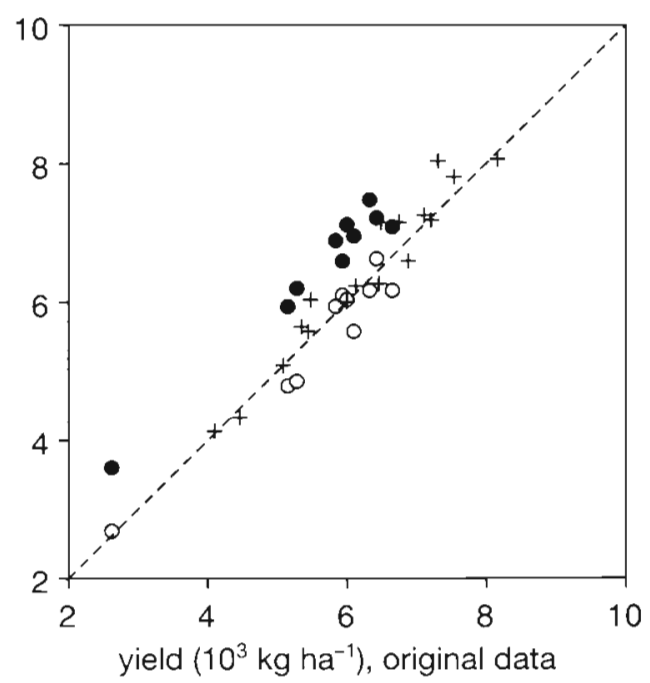

Fig. 3. Comparison between simulated water-limited spring wheat yield using daily weather data from the original set (Wageningen, 1961 to 1987) and simulated yield when temperature data in this set were replaced by temperature data from another station: (O) De Bilt, 1976 to $1985_{i}$ (•) De Kooy, 1976 to $1985 ;(+)$ De Bilt, 1961 to 1975 and 1986 to 1987 
the growing season) results in a very complicated system through which the effects of inaccuracies in temperature data on the simulated water-limited yield are not easy to explain.

To study the effect of overestimating vapour pressure deficit only (as a result of overestimating temperature) on the water requirements of the crop, a simulation run was made in which vapour pressure deficit was increased by $1.0 \mathrm{mb}$ on all days (temperature was not changed). Total water requirements of the crop increased by $10 \%$ (about $40 \mathrm{~mm}$ season $^{-1}$ ) in all years. The total effect of temperature overestimation on crop water requirements will, however, be smaller. As shown in Nonhebel (1994a), duration of the growing period is determined by temperature. An increase in temperature of $1^{\circ} \mathrm{C}$ results in a reduction in the crop growing season of about $10 \mathrm{~d}$. Under Dutch conditions, a spring wheat crop uses 3 to $4 \mathrm{~mm} \mathrm{~d}^{-1}$ Therefore the effect of temperature on water requirements of the crop, acting through duration of the growing season. compensates for its effects through vapour pressure deficit. So, in general, deviations in simulated yield as a result of inaccuracies in temperature data cannot be explained by changed water requirements of the crop. However, in Nonhebel (1994a) it was shown that in a number of years a temperature decrease resulted in a shortening of the growing period instead of in a lengthening. In those years, inaccuracies in temperature data affected the water requirements of the crop. In 1973, for example, underestimation of temperature resulted in a shorter growing season, and thus in an underestimation of the crop water requirements (combined effect of a shorter growing season and a lower vapour pressure deficit), which led to an overestimation of the water-limited yield in that year (Fig. 1). Through this effect of temperature on water requirements of the crop, fewer years occurred in which underestimation of temperature resulted in underestimation of water-limited yield than was found for the simulation of potential yield (Nonhebel 1994a).

Under Dutch conditions, spring wheat crops mature in August. In this month precipitation falls mainly as showers (Können 1983). An inaccuracy of $1^{\circ} \mathrm{C}$ in temperature results in a shift in the end of the growing season of 10 to $15 \mathrm{~d}$. The large deviations in the amount of precipitation during the growing season are caused by heavy showers (10 to $20 \mathrm{~mm}$ ) during the $10 \mathrm{~d}$ that the crop is delayed or advanced. The effect of this extra water on the simulated yield is small. Leaf area is strongly declining in this period as a result of the ripening of the crop. Weather conditions during the last 2 wk of the growing season therefore have only a small effect on the final yield.

Thus, inaccuracies in temperature data hardly affect the water requirements of the crop or the amount of water available to it. In very low-yield years $(2$ to $5 \mathrm{t}$ $\mathrm{ha}^{-1}$ ) the amount of water available is the major limiting factor. Since temperature does not affect this amount, the sensitivity of the model to inaccuracies in temperature data is less under dry conditions. This was also found for the effect of using average values over $10 \mathrm{~d}$ or $1 \mathrm{mo}$ and data from another station: the deviation in dry years is smaller than in wet years (Figs. $2 \& 3$ ).

Overestimation of the yield in low-yield years and underestimation in high-yield years when climatic averages are used (Fig. 3) can be explained as follows. Weather variables are often correlated. On warm days, for instance, radiation levels will be high and there will be no precipitation. Therefore dry summers are usually summers with higher-than-average temperatures. In dry summers yield is low due to the water shortage of the crop. So when average temperatures over 30 yr are used, temperatures are underestimated in the lowyield (dry) years, resulting in overestimation of the yield. In years with sufficient water, temperatures are lower than average, so use of average values overestimates temperature, resulting in underestimation of the yield.

\section{Conclusions}

Underestimation of air temperature results in overestimation of the yield, and vice versa. The model is less sensitive to inaccuracies in air temperature data under dry conditions than under wet conditions. In most years the water status of the crop is not influenced by these inaccuracies. Use of averages over months or years should be avoided. Use of data from a nearby station is the best solution for replacing missing air temperature values.

\section{GLOBAL RADIATION}

\section{Introduction}

Global radiation influences 2 important processes affecting water-limited production. First, it drives photosynthesis. The effect of inaccuracies in global radiation data on photosynthesis is discussed in Nonhebel (1994a). Due to the non-linear relation between light intensity and assimilation rate, an overestimation of global radiation by $10 \%$ led to an overestimation of the yield by $5 \%$, underestimation by $10 \%$ led to an underestimation of the yield by $9 \%$ and use of average values led to an overestimation of the yield by 10 to $30 \%$

The other process in which global radiation plays an important role is evapotranspiration of the crop and the 
soil. An increase in global radiation leads to an increase in evapotranspiration (Monteith 1965). In years in which enough water is available, increased global radiation leads to a higher yield (potential production level). However, when water is limiting, higher global radiation levels can increase water shortage, which can counterbalance the effect of higher assimilation rates.

\section{Results}

The effect of under- and overestimation of global radiation by $10 \%$ on simulated water-limited yield is shown in Fig. 4. In low-yield years overestimation resulted in underestimation of yield, and underestimation resulted in overestimation of yield. In high-yield years the opposite effect was found. The deviation in simulated yield in high-yield years was smaller than that for the potential production simulations (Nonhebel 1994a).

Use of averages over short periods (10 d or $1 \mathrm{mo}$ ) had hardly any effect in low-yield years, but in highyield years the yield was overestimated (Fig. 5). Climatic averages resulted in overestimation of yield by nearly $1 \mathrm{t} \mathrm{ha}^{-1}$ in all years (Fig. 5). Use of data from De Bilt had the same effect on simulated yield as found in the potential production simulation: only a small deviation was found (Fig. 6). Data from De Kooy resulted in underestimation of yield in low-

yield $\left(10^{3} \mathrm{~kg} \mathrm{ha}^{-1}\right)$, changed radiation data

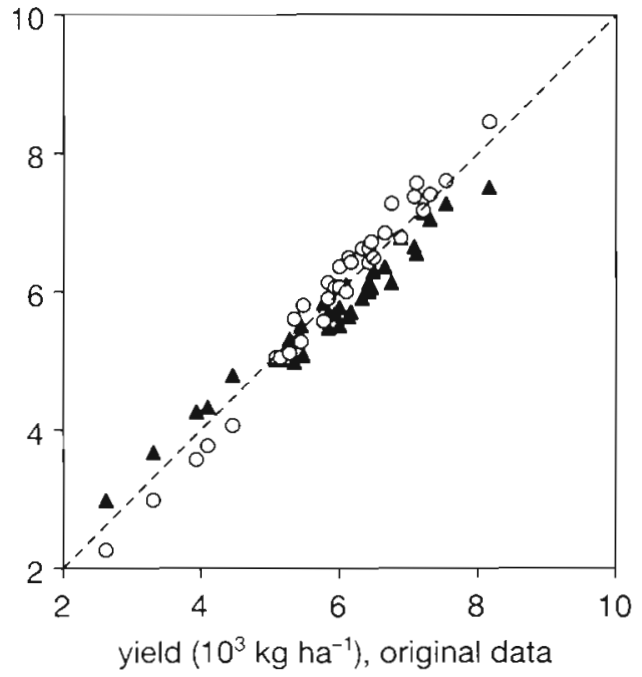

Fig. 4. Comparison between water-limited spring wheat yield simulated with the original weather data set (Wageningen, 1954 to 1987 ) and simulated yield when daily global radiation in the original set was increased $(\mathbf{O})$ or decreased (A) by $10 \%$ yield $\left(10^{3} \mathrm{~kg} \mathrm{ha}^{-1}\right)$, average radiation data

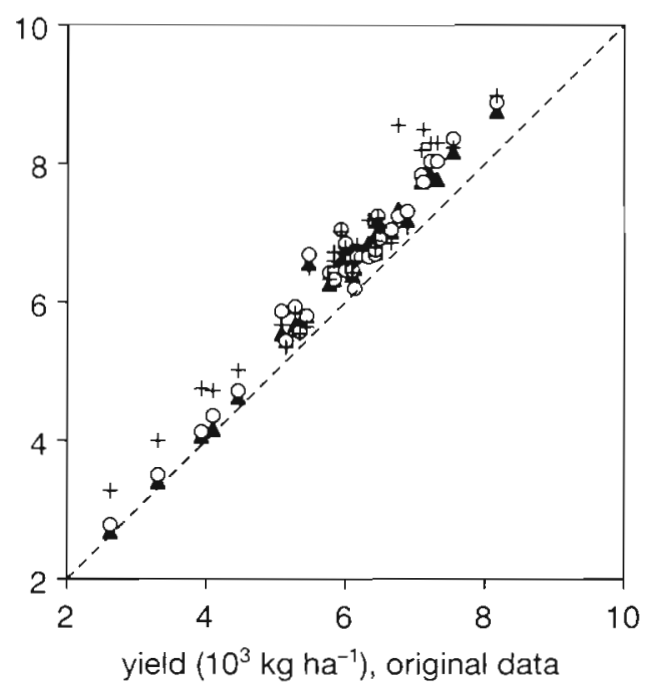

Fig. 5. Comparison between simulated water-limited spring wheat yield using daily weather data from the original data set (Wageningen, 1954 to 1987) and simulated yield when daily values for global radiation were estimated from average values: ( 1 ) $10 \mathrm{~d},(0)$ monthly averages, $(+)$ climatic averages

yield years and overestimation of the yield in highyield years (Fig. 6).

Use of sunshine duration data to estimate global radiation led to a very small deviation in the simulation results (Fig. 7 ).

\section{yield $\left(10^{3} \mathrm{~kg} \mathrm{ha}^{-1}\right)$, rad. data from other station}

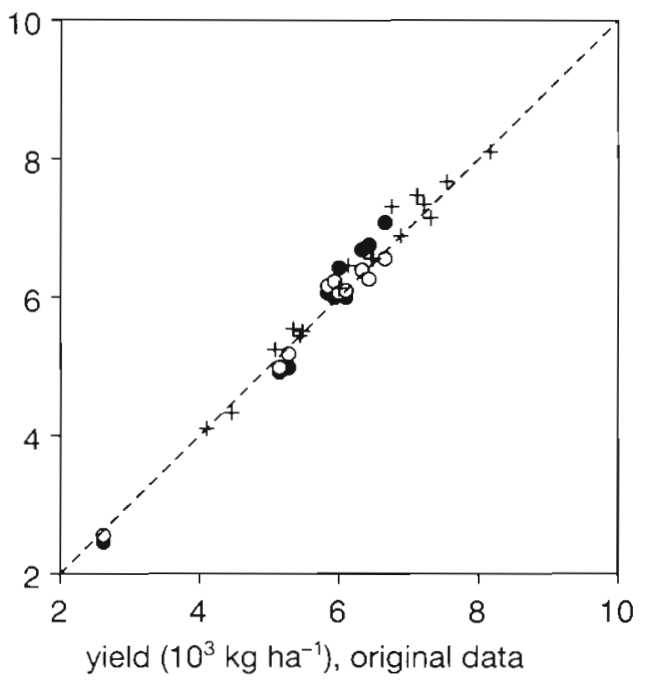

Fig. 6. Comparison between simulated water-limited spring wheat yield using the original data from Wageningen (1961 to 1987) and simulated yield when global radiation data in this set were replaced by global radiation data from another station: (O) De Bilt, 1976 to 1985; (@) De Kooy, 1976 to 1985

(+) De Bilt, 1961 to 1975 and 1986 to 1987 
yield $\left(10^{3} \mathrm{~kg} \mathrm{ha}^{-1}\right)$, sunshine duration data

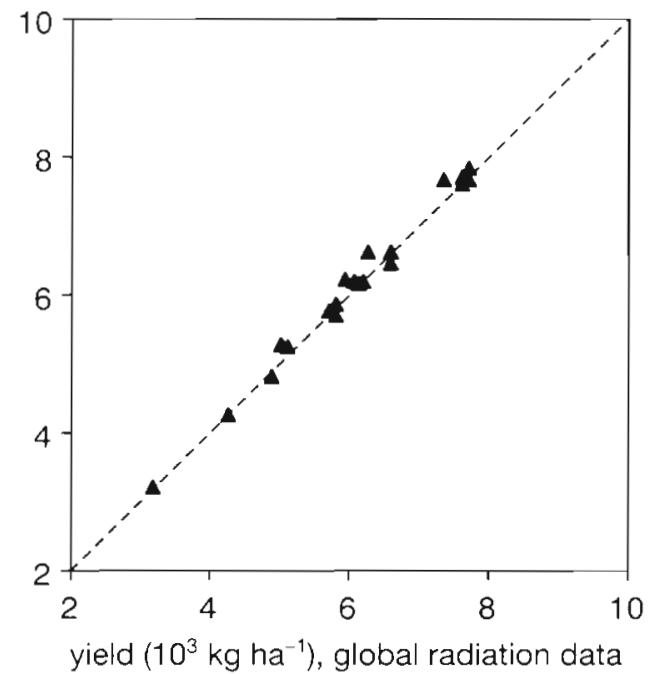

Fig. 7. Comparison between simulated water-limited spring wheat yield using daily weather data from De Bilt (1961 to 1980 ) and simulated yield when global radiation data were estimated from sunshine duration data from this station

\section{Discussion}

In cereals, most of the dry matter is produced during the vegetative part of the growing season. The yield (grains), however, is formed during the grain filling period at the end of the growing season. Under Dutch conditions water hardly ever limits growth during the vegetative period of the crop - instead, water shortage occurs during the grain filling period. In dry years, overestimation of radiation leads to higher dry matter production and higher transpiration rates during the vegetative period. Thus the amount of water available at the start of the grain filling period is smaller, resulting in a greater water shortage and a lower yield (Fig 4). Underestimation of radiation produces the opposite effect on the simulated yield Lower radiation levels result in a lower transpiration during the vegetative period of the crop. Hence more water is available during the grain filling period, resulting in less shortage and a higher yield. In years in which yields of $6 \mathrm{tha}^{-1}$ are achieved, the effect changes. In these years, the effect of increased water shortage is counterbalanced by higher photosynthetic rates. In high-yield years water shortage is rare. Production is water-limited on only a few days during the whole season. On these dry days, overestimation of radiation will not increase the production. Underestimation of radiation. results in underestimation of transpiration during the season. Consequently more water is available, and hence production is higher on dry days. Therefore water-limited production is less sensi- tive to inaccuracies in radiation data than potential production.

Radiation levels in De Kooy are higher than in Wageningen (Nonhebel 1994a). So, in general, radiation is overestimated when data from De Kooy are used, resulting in underestimation of the yield in dry years and overestimation of the yield in wet years (Fig. 6)

The relation between radiation and transpiration is linear, so use of average values will not affect the total transpiration over the season. This implies that use of averages over $10 \mathrm{~d}$ or 1 mo does not affect the simulated amount of water available at the start of the grain filling period. In dry years, therefore, the effect of using average values on the simulation results is very small (Fig. 5). In high-yield years the non-linear relation between radiation and photosynthesis (Fig. 11 in Nonhebel 1994a) explains the overestimation of the yield when averagos are used.

In general, dry years are years with high radiation levels and high temperatures. So, use of average values over several years implies that radiation is underestimated in the dry years, resulting in overestimation of the yield (Fig. 4), and that radiation is overestimated in the dark, wet years, also resulting in overestimation of the yield.

\section{Conclusions}

Water-limited production is less sensitive to inaccuracies in global radiation data than potential production. In dry years, overestimation of radiation leads to underestimation of the yield, and in wet years to overestimation. Under dry conditions averages over short periods can be used. In wet conditions use of averages must be avoided. When data are missing they can best be replaced by estimates based on sunshine duration data, or by data from a nearby station.

\section{PRECIPITATION}

\section{Introduction}

In the simulation model used, precipitation during the growing season, plus the moisture in the soil profile at sowing, determines the amount of water available for crop growth. However, not all the water that reaches the soil as precipitation is available for crop growth. Part of it evaporates from the top layer of the soil, and part descends to deeper soil layers. Only moisture in the rooting zone of the profile is available for uptake by the plant.

The WMO (1983) recommends that amounts of precipitation be determined with an accuracy of $2 \%$. It is 
no problem to determine the amount of precipitation in a rain gauge with this accuracy. However, the amount of precipitation reaching the soil surface can deviate considerably from the amount collected in a rain gauge (de Zeeuw 1963, Rodda 1971, Sevruk 1989) A rain gauge is an obstacle in the air stream and causes turbulence. Raindrops entering the gauge are hampered by this turbulence, and thus less rain is collected in the gauge than reaches the soil. The effect can be very large in situations with strong wind and light rain or snow. It was found that at windy sites, a gauge at a height of $1.5 \mathrm{~m}$ above ground registered $15 \%$ less precipitation than one on the ground, and a gauge at $0.4 \mathrm{~m}$ registered $5 \%$ less (de Zeeuw 1963, Buishand \& Velds 1980). Installation of a gauge in the ground is not always possible, due to technical problems such as high groundwater tables, rocky, unlevel surfaces, etc. No standards exist with respect to the height at which precipitation should be measured, so a deviation of $10 \%$ or more can occur between precipitation recorded and the amount of water reaching the soil. Here the effect of $10 \%$ over- and underestimation of the precipitation on simulated yield is examined.

An important aspect of precipitation is its spatial variability. Therefore rainfall is recorded at far more sites than are the other meteorological variables (Duivenvoorden 1986). The KNMI (Royal Netherlands Meteorological Institute) recognizes 15 rainfall districts, and precipitation data from over 300 stations are published, while daily maximum and minimum air temperatures are recorded at only about 50 stations. Summer showers in particular can cause large local variation in the daily precipitation. In The Netherlands, differences in daily precipitation of $30 \mathrm{~mm}$ over distances of $5 \mathrm{~km}$ are found (de Bruin 1973). Because of this local variability it can hardly be expected that the amount of precipitation in De Bilt $(40 \mathrm{~km}$ away from Wageningen) will be comparable to that in Wageningen. Thus, precipitation data from Arnhem $(10 \mathrm{~km}$ from Wageningen) in 1975 were used to determine the effect of using data from a more nearby station on simulated yield.

\section{Results and discussion}

Overestimation of precipitation leads to an increase in the amount of water available to a plant, and so to an increased yield; underestimation leads to a decline in yield (Fig. 8). Over- or underestimation of precipitation by $10 \%$ does not, however, result in an exact $10 \%$ increase or decrease in the amount of water available. When, for instance, the profile is saturated, the $10 \%$ extra water will percolate to deeper soil layers and will never be available to the plant. In high-yield (wet) yield $\left(10^{3} \mathrm{~kg} \mathrm{ha}^{-1}\right)$, changed precip. data

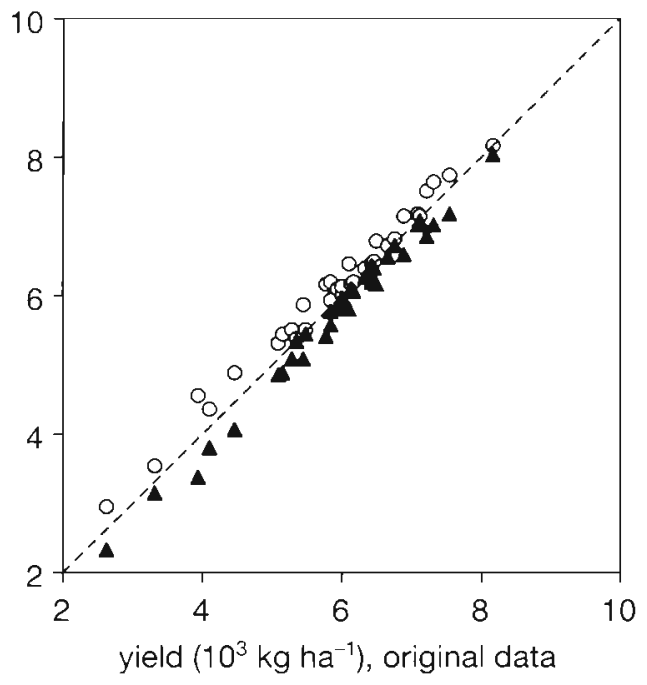

Fig. 8. Comparison between water-limited spring wheat yield simulated with the original weather data set (Wageningen, 1954 to 1987) and simulated yield when daily precipitation in the original set was increased $(0)$ or decreased $(\boldsymbol{\Lambda})$ by $10 \%$

years the effect of inaccuracies in precipitation data on the final yield is very small, because production is only affected on those very few days that water is limiting growth. In dry years, water limitation occurs far more often, and the effect of inaccuracies in precipitation data on final yield is therefore much larger.

The average deviation from the original precipitation data is given for the various estimation methods used (Table 1). In the 10 years considered, the annual precipitation in De Bilt was about $100 \mathrm{~mm}$ higher

Table 1. Average deviation in precipitation $\left(\mathrm{mm} \mathrm{d}^{-1}\right)$ between the original value $\left(x_{01}\right)$ on Day $i$ in the data set from Wageningen and the estimated value $\left(x_{e i}\right)$ using various estimation methods. Methods considered are: data from another station (De Bilt, De Kooy and Arnhem) and average values from Wageningen over various intervals $(10 \mathrm{~d}, 1 \mathrm{mo}$ or $30 \mathrm{yr}$ climatic data). $n$ is the number of days: 365 for De Bilt (1975) and Arnhem (1975), and 3650 for the other estimation methods (1976 to 1985)

\begin{tabular}{|lcc|} 
& $\frac{\sum_{i=1}^{n}\left(x_{0 i}-x_{e i}\right)}{n}$ & $\sqrt{\frac{\sum_{i=1}^{n}\left(x_{01}-x_{e i}\right)^{2}}{n}}$ \\
\hline De Bilt & -0.3 & 4.1 \\
De Kooy & -0.1 & 4.5 \\
10 d averages & 0.0 & 3.6 \\
Monthly averages & 0.0 & 3.8 \\
Climatic averages & 0.2 & 4.0 \\
Arnhem, 1975 & 0.0 & 2.3 \\
De Bilt, 1975 & 0.2 & 4.8 \\
\hline
\end{tabular}


(365 $\times 0.3 \mathrm{~mm})$, and that in De Kooy about $40 \mathrm{~mm}$ higher, than in Wageningen. This is in accordance with the average annual precipitation over 1951 to 1980 (Können 1983). The deviation in 1975 is also given: in this year, the amount of precipitation in De Bilt was about $80 \mathrm{~mm}$ less than in Wageningen; data from the nearer station Arnhem resulted in smaller deviations.

Since the $10 \mathrm{~d}$ and monthly averages are based on the daily data set (i.e. Wageningen), average precipitation is the same, and the deviation in the first column is zero. Climatic data are based on data from 1954 to 1983 and cover a different period, resulting in a small deviation. Based on this time interval, average annual precipitation in Wageningen was $0.2 \times 365=80 \mathrm{~mm}$ less than in the period 1976 to 1985.

In contrast with the other weather variables, use of precipitation data from another station resulted in a larger absolute deviation (Table 1, column 2) from the original value than the estimates based on average values. Moreover, the effect of these estimation methods on simulation results cannot be completely explained from the deviations calculated.

Although deviation from the original values was larger, data from another station gave, especially in dry years, better simulation results than the average data (Figs. $9 \& 10$ ). In wet years the results were comparable to those of average data, which is reasonable since in wet years the model is less sensitive to inaccuracies in precipitation data (Fig. 8). In dry years averages over $10 \mathrm{~d}$ or $1 \mathrm{~m}$ led to underestimation of the

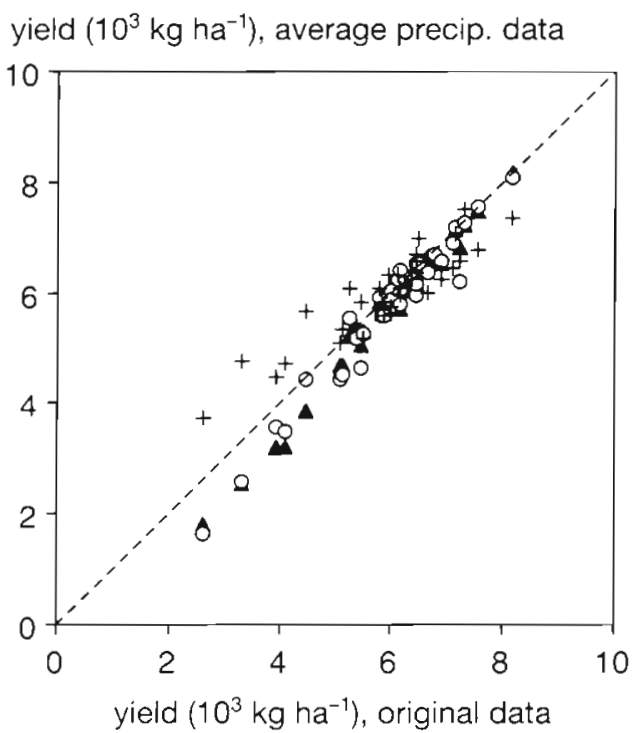

Fig. 9. Comparison between simulated water-limited spring wheat yield using daily weather data from the original data set (Wageningen, 1954 to 1987) and simulated yield when daily precipitation was estimated from average values:

(A) $10 \mathrm{~d},(0)$ monthly averages, $(+)$ climatic averages yield $\left(10^{3} \mathrm{~kg} \mathrm{ha}^{-1}\right)$, precip. data from other stn

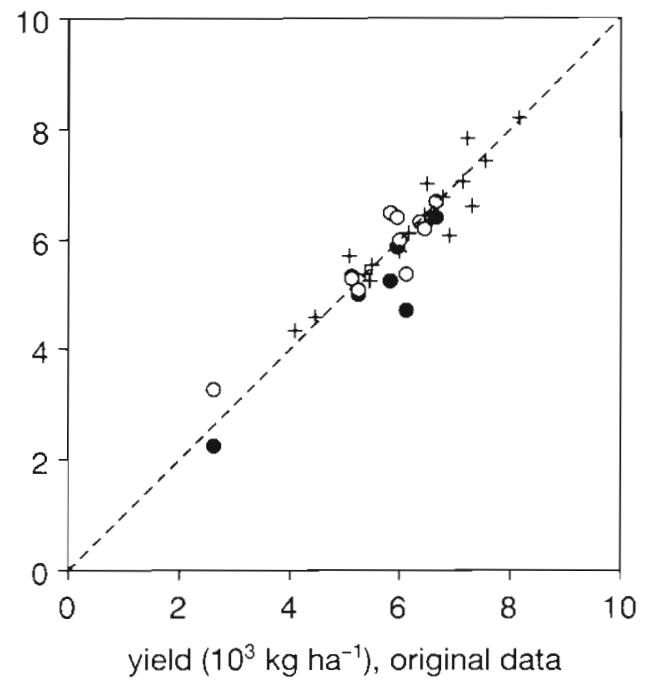

Fig. 10. Comparison between simulated water-limited spring wheat yield using daily weather data from the original set (Wageningen, 1961 to 1987) and simulated yield when precipitation data in this set were replaced by precipitation data from another station: (O) De Bilt, 1976 to $1985_{\text {; }}$ (e) De Kooy, 1976 to 1985 ( +) De Bilt, 1961 to 1975 and 1986 to 1987

yield, while climatic averages led to overestimation (Fig. 9).

The amount of water available to a crop is largely influenced by the distribution of precipitation. One shower of $50 \mathrm{~mm}$ has a different effect to 25 showers of $2 \mathrm{~mm}$. Water in the top layer of the soil is subject to evaporation, and evaporation stops when this layer is dry. Many small showers imply that the layer is wetted regularly and that a relatively large amount of water is lost by evaporation. This is in contrast with one big shower, in which the top layer is wetted only once. Use of averages implies that on every day about $2 \mathrm{~mm}$ of rain falls; thus, evaporation losses are overestimated, which results in an important underestimation of the yield in dry years.

Use of climatic data implies that in all years the same amount of precipitation falls $(760 \mathrm{~mm})$, which in dry years results in an overestimation of the total precipitation. This overestimation is larger than the increased evaporation losses due to rain occurring every day, and so yield is overestimated.

When data from another station are used, the rainfall pattern of dry and wet days is retained and hence evaporation losses are not overestimated, so that a better simulation result is obtained in dry years (Fig. 10). In 1975 rainfall data from De Bilt resulted in an underestimation of the yield by over $10 \%$, while data from Arnhem resulted in only a $2 \%$ underestimation. 
For crop growth simulation purposes, models have been developed to simulate rainfall distribution based on climatic averages. The effect of using these rainfall simulators on simulated yield is beyond the scope of this thesis; for a description of these rainfall simulators and their results, see Geng et al. (1986)

\section{Conclusions}

In precipitation data, inaccuracies of $10 \%$ can be expected. Precipitation generally is underestimated. In years with water shortage, inaccuracies in rainfall data can cause deviations in simulated yields of over $15 \%$. Estimates of missing rainfall data based on averages are meaningless and must be avoided. But, as a result of the regional variation of rainfall, precipitation data from a station $40 \mathrm{~km}$ away cannot be used to replace missing values.

\section{VAPOUR PRESSURE}

\section{Introduction}

In the model vapour pressure is used to determine the evaporative demand of the atmosphere (Eq. 2). Overestimation of vapour pressure leads to underestimation of vapour pressure deficit and thus to underestimation of evapotranspiration. Vapour pressure is generally measured with a psychrometer (WMO 1983), with which the air humidity is determined from the difference in wet and dry bulb temperature. In Nonhebel (1994a) it is shown that inaccuracies of $1^{\circ} \mathrm{C}$ can be expected in temperature measurements. An inaccuracy of $1^{\circ} \mathrm{C}$ in the difference between the wet and dry bulb temperature, then, results in an inaccuracy of about $1.0 \mathrm{mb}$ in vapour pressure. Inaccuracies in air temperature measurements, however, are mainly caused by the location of the instrument. The temperature difference between 2 thermometers at the same spot is not likely to be influenced by this type of error, so the inaccuracy in the vapour pressure data will be smaller than $1.0 \mathrm{mb}$. In a comparative study between several types of psychrometer, deviations of up to $0.5 \mathrm{mb}$ between different instruments were found (Kramer et al. 1954). The effect of a $0.5 \mathrm{mb}$ inaccuracy in vapour pressure data on simulated yield is investigated in this section.

The moisture content of the air is not always recorded as vapour pressure: at some stations the relative humidity of the air is measured. In contrast to vapour pressure, relative humidity is temperaturedependent. When air temperature is known, vapour pressure can be derived from relative humidity data by multiplying saturated vapour pressure at this air temperature (Eq. 1) with the relative humidity. However, in most data sets the temperature at which relative humidity was determined is not given - at best, only the time of day at which this was done (often early in the morning) In most temperature data sets the only values reported are minimum and maximum temperatures. The simplest method of deriving vapour pressure from relative humidity data is to determine saturated vapour pressure at the minimum temperature on a given day, assuming that the early morning temperature is very near the minimum temperature.

Another possibility is to estimate the temperature at the moment the measurement was done. According to Parton \& Logan (1981), the air temperature at any moment during daytime $\left(T_{\mathrm{h}}\right)$ can be estimated from the minimum and maximum air temperature as:

$$
T_{\mathrm{h}}=T_{\min }+\left(T_{\max }-T_{\min }\right) \sin \left(\pi \frac{H-12+0.5 D}{D+3}\right)
$$

where $T_{\min }$ is minimum air temperature $\left({ }^{\circ} \mathrm{C}\right), T_{\max }$ is maximum air temperature $\left({ }^{\circ} \mathrm{C}\right), D$ is daylength (h) and $H$ is time of day (h).

Data for both vapour pressure and relative humidity were available from Wageningen only for 1979. Relative humidity was determined at 09:00 h (Central European Time, CET). The recorded vapour pressure was compared with the vapour pressure calculated from relative humidity data using minimum air temperature and the temperature estimated at 09:00 h CET with Eq. (3).

\section{Results and discussion}

In low-yield years, overestimation of vapour pressure by $0.5 \mathrm{mb}$ resulted in a small overestimation of the simulated yield, and underestimation in a small underestimation of the yield (Fig. 11). In high-yield years, inaccuracies in vapour pressure had hardly any effect on the simulation results. In the model, overestimation of vapour pressure results in underestimation of evapotranspiration. In dry years, this leads to underestimation of the water shortage and overestimation of the yield; in wet years, underestimation of the water shortage influences simulated production on only a few days. Even in dry years the model is not very sensitive to inaccuracies in vapour pressure data: deviations in simulated yield of less than $5 \%$ were found.

Deviation from the original value was small for all estimation methods used (Table 2). Variation of vapour pressure from day to day is small, so use of average values resulted in a small deviation from the original data in comparison with other weather variables. The low sensitivity of the model to inaccurate vapour pres- 
yield $\left(10^{3} \mathrm{~kg} \mathrm{ha}^{-1}\right)$, changed vap. press. data

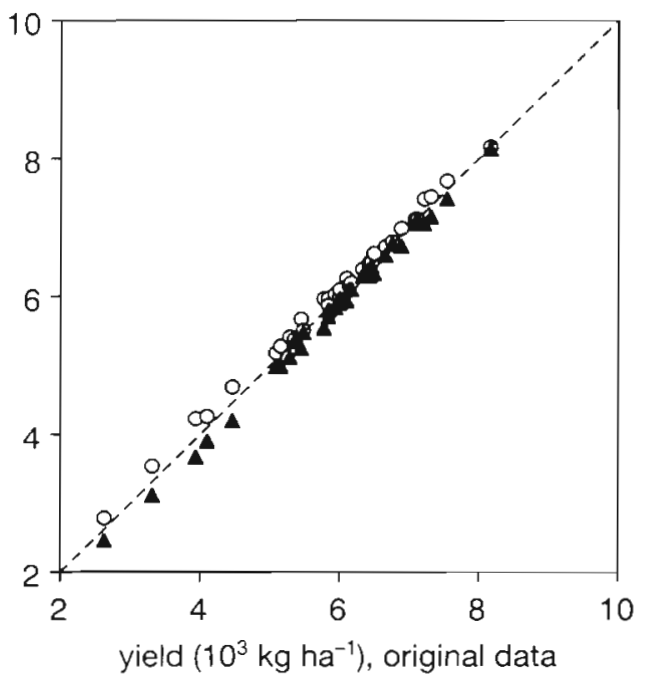

Fig. 11 Comparison between water-limited spring wheat yield simulated with the original weather data set (Wageningen, 1954 to 1987) and simulated yield when daily vapour pressure in the original set was increased $(0)$ or decreased (A) by $0.5 \mathrm{mb}$

Table 2. Average deviation in vapour pressure $(\mathrm{mb})$ between the original value $\left(x_{0 i}\right)$ on Day $i$ in the data set from Wageningen and the estimated value $\left(x_{e 1}\right)$ using various estimation methods. Methods considered are: data from another station (De Bilt, De Kooy) and average values from Wageningen over various intervals ( $10 \mathrm{~d}, 1$ mo or 30 yr climatic data). $n$ is the number of days: 3650 (1976 to 1985)

\begin{tabular}{|c|c|c|}
\hline & $\frac{\sum_{i=1}^{n}\left(x_{\mathrm{o} i}-x_{\mathrm{e} i}\right)}{n}$ & $\frac{\sum_{i=1}^{n}\left(x_{o i}-x_{e}\right)^{2}}{n}$ \\
\hline De Bilt & -0.3 & 1.3 \\
\hline De Kooy & -0.4 & 1.3 \\
\hline $10 \mathrm{~d}$ averages & 0.0 & 1.6 \\
\hline Monthly averages & 0.0 & 2.0 \\
\hline Climatic averages & -0.3 & 2.2 \\
\hline
\end{tabular}

sure data, the fact that severe water shortage occurred in only a few years, and the fact that variability of the vapour pressure is low explains the good results obtained when average data were used (Fig. 12).

Vapour pressure levels in De Bilt and De Kooy are 0.3 to $0.4 \mathrm{mb}$ higher than in Wageningen. Due to the slight overestimation of vapour pressure when data from these stations were used, yield was overestimated in low-yield years. In high-yield years hardly any effect was found (Fig. 13). Data from another station can be used even when it is in another climatic district (Fig. 13). yield $\left(10^{3} \mathrm{~kg} \mathrm{ha}^{-1}\right)$, average vap. press. data

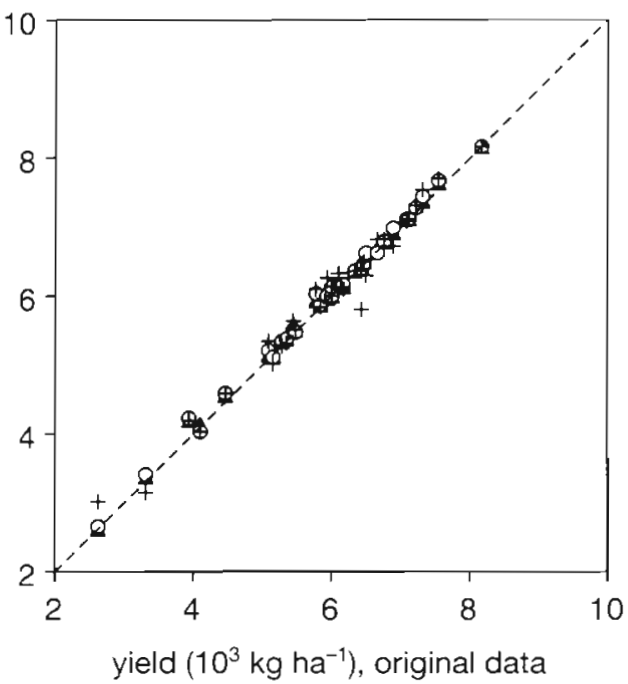

Fig. 12. Comparison between simulated water-limited spring wheat yield using daily weather data from the original data set (Wageningen, 1954 to 1987) and simulated yield when daily vapour pressure was estimated from average values:

(4) $10 \mathrm{~d},(0)$ monthly averages, $(+)$ climatic averages

yield $\left(10^{3} \mathrm{~kg} \mathrm{ha}^{-1}\right)$, vap. press. from other stn

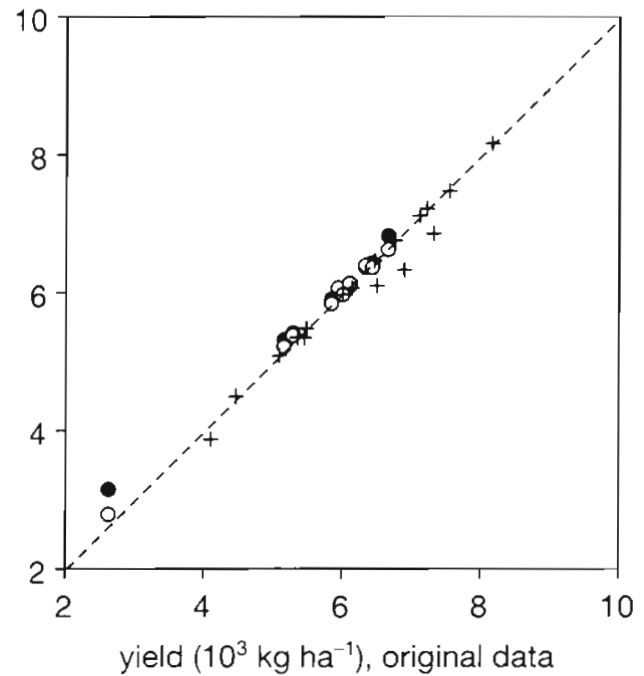

Fig. 13. Comparison between simulated water-limited spring wheat yield using daily weather data from Wageningen (1961 to 1987) and simulated yield when vapour pressure data in the original set were replaced by vapour pressure data from another station: (o) De Bilt, 1976 to 1985; (•) De Kooy, 1976 to 1985; (+) De Bilt, 1961 to 1975 and 1986 to 1987

Use of 09:00 h temperature estimates provided a much better estimation of vapour pressure than use of the minimum temperature (Fig. 14) ${ }_{i}$ the difference in estimates was large (up to $10 \mathrm{mb}$ ), especially on days 
estimated vapour pressure $(\mathrm{mb})$

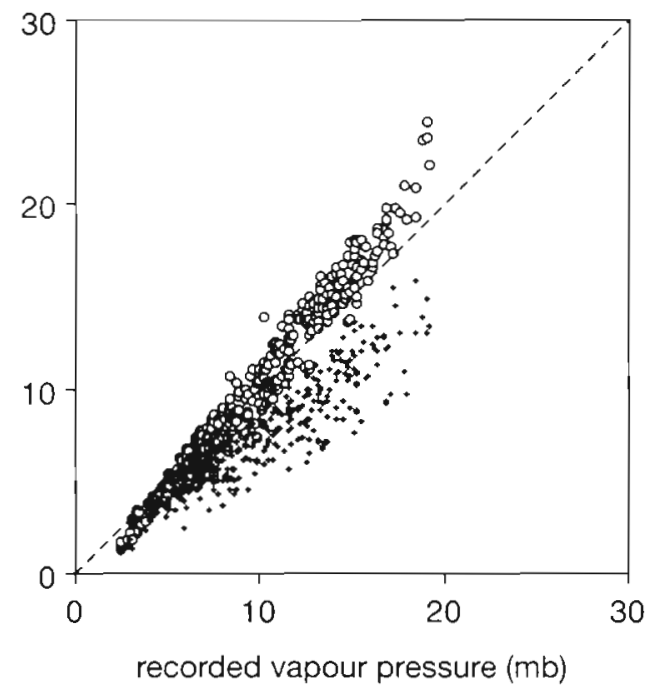

Fig. 14. Comparison between measured vapour pressure in Wageningen in 1979 and estimated values from relative humidity data, using minimum air temperature $(+)$ and the estimated 09:00 h air temperature (0)

with high values for vapour pressure. High values for vapour pressure occur during summer when temperatures are high. In this season the difference between the minimum temperature occurring at night and the temperature at 09:00 $\mathrm{h}$ is very large. In summer, the sun rises at about 05:00 h, so by 09:00 h the sun has been heating the earth for $4 \mathrm{~h}$. In winter the sun rises at 08:30 $\mathrm{h}$, and the difference between the minimum temperature and the temperature at 09:00 $\mathrm{h}$ will be very small.

The effect on simulation results of relating relative humidity to minimum temperature was very small for 1979: an underestimation of only $1 \%$ was found. However, use of averages, data from another station or correlation of relative humidity to the 09:00 h temperature led to even better results (less than $0.1 \%$ deviation). Because 1979 was a very wet year, inaccuracies in vapour pressure data had almost no effect on simulation results. In dry years, a very large underestimation of the yield can be expected when relative humidity data are related to the minimum temperature.

\section{Conclusions}

Inaccuracies of $0.5 \mathrm{mb}$ can occur in vapour pressure data. The model is not sensitive to these inaccuracies. In very dry years a deviation in simulated yield of $5 \%$ can be expected. When data are missing they can be replaced by average values (even averages over sev- eral years) or data from another station. Relative humidity data can be used to estimate vapour pressure, but it is essential to relate relative humidity to the air temperature at the observation time.

\section{WIND SPEED}

\section{Introduction}

In the model, daily average wind speed is used to determine the resistance of the crop against transpiration (Goudriaan 1977). A high wind speed results in a low resistance and so in a higher evapotranspiration. Wind speed varies with height above ground, and an obstacle has a large effect on the wind speed in the vicinity of the obstacle (Wieringa \& Rijkoort 1983). According to the WMO (1983), wind speed should be measured at $10 \mathrm{~m}$ above ground in open terrain, with an accuracy of $10 \%$. Open terrain is defined as 10 times the height away from the nearest obstruction. In this section the effect of a $10 \%$ deviation in wind speed data on simulation results is examined.

In most crop growth models wind speed at crop height is required. Wind speed at the crop surface is about half that at $10 \mathrm{~m}$ above ground (logarithmic wind profile). When the wind speed is not corrected with respect to crop height, the model overestimates the wind speed at crop height and so overestimates the transpiration. Another problem with wind speed data is that some stations publish these data in units of knots $\left(0.5 \mathrm{~m} \mathrm{~s}^{-1}\right)$. When these data are not corrected to the proper units, wind speed is overestimated by $100 \%$. Therefore the effect of overestimating wind speed by a factor of 2 is also studied.

\section{Results and discussion}

The effect on simulated yield of over- and underestimating wind speed by $10 \%$ was very small, causing the yield to be over- or underestimated by only $2 \%$ in dry years and even less in wet years. The effect of doubling or halving wind speed (due to a wrong reference level or incorrect units) on the simulated yield is shown in Fig. 15: in dry years a deviation in simulated yield of $10 \%$ was obtained. In other years no effect was found. So, overall, the model is not sensitive to inaccuracies in wind speed data.

The average wind speed in De Bilt for the period 1976 to 1985 was $0.3 \mathrm{~m} \mathrm{~s}^{-1}$ higher, and in De Kooy $3 \mathrm{~m}$ $\mathrm{s}^{-1}$ higher, than in Wageningen (Table 3), which is in accordance with data in Wieringa \& Rijkoort (1983). Use of average values implied a small deviation from the original data. 
yield $\left(10^{3} \mathrm{~kg} \mathrm{ha}^{-1}\right)$, changed wind speed

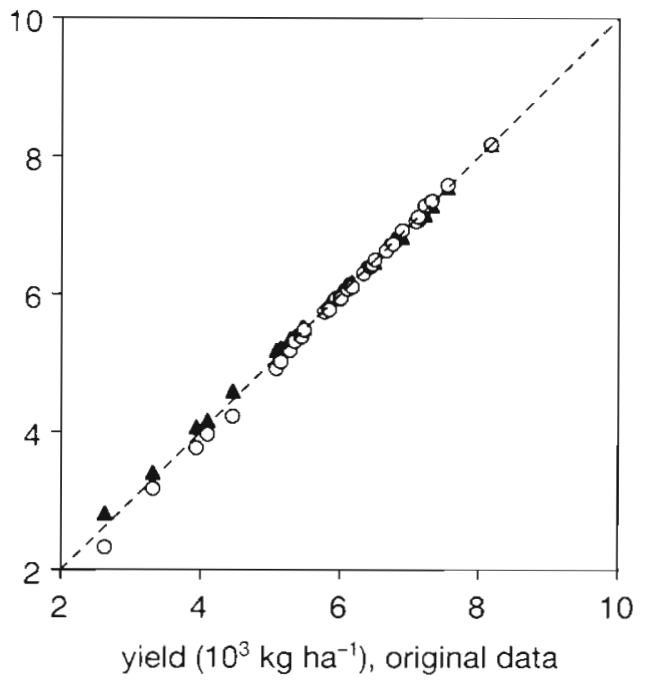

Fig. 15. Comparison between water-limited spring wheat yield simulated with the original weather data set (Wageningen, 1954 to 1987) and simulated yield when wind speed in the original set was doubled $(0)$ or halved

Table 3. Average deviation in wind speed $\left(\mathrm{m} \mathrm{s}^{-1}\right)$ between the original value $\left(x_{0 i}\right)$ on Day $i$ in the data set from Wageningen and the estimated value $\left(x_{e l}\right)$ using various estimation methods Methods considered are data from another station (De Bilt, De Kooy) and average values from Wageningen over various intervals $(10 \mathrm{~d}, 1$ mo or $30 \mathrm{yr}$ climatic data $) . n$ is the number of days: 3650 (1976 to 1986)

\begin{tabular}{|lcc|}
\hline & $\frac{\sum_{i=1}^{n}\left(x_{01}-x_{\mathrm{el}}\right)}{n}$ & $\sqrt{\frac{\sum_{i=1}^{n}\left(x_{01}-x_{\mathrm{e},}\right)^{2}}{n}}$ \\
\hline De Bilt & -0.3 & 0.9 \\
De Kooy & -3.0 & 3.4 \\
10d averages & 0.0 & 1.1 \\
Monthly averages & 0.0 & 1.2 \\
Climatic averages & 0.0 & 1.3 \\
\hline
\end{tabular}

Use of average values, even those over several years, and data from De Bilt resulted in the same deviation in simulated yield ( $2 \%$ in dry years). When data from De Kooy were used, although wind speed in this part of the country is $30 \%$ higher than in the centre, the effect was small: the simulated yield was underestimated by less than $3 \%$ in nearly all years.

\section{Conclusions}

The model is not sensitive to irregularities in wind speed data and there is no need to take the effects of inaccuracies in these data into account. When wind speed data are missing, they can be replaced by average data (even averages over several years) or by data from another station. It is important to verify the height at which data have been recorded and the units used, since frequent mistakes in reference height or units can result in deviations in simulated yield of $10 \%$ in dry years

\section{RANDOM ERRORS IN ALL WEATHER DATA}

In the previous sections the effect of inaccuracies in individual weather variables on simulation results was described. In practice, errors will occur in all data on all days. Often data are not systematically over- or underestimated. Therefore the effect of random errors in all data on the simulation results was examined.

It was assumed that each weather variable was under- or overestimated with the level of inaccuracy used for that variable in this study. A random number generator was used to generate a value $x$ in the interval 0 to 1 . When $x$ was less than 0.5 the value of the weather element in the original data set was decreased with its assigned inaccuracy, and when $x$ was equal to or greater than 0.5 the value was increased. This was done for all weather elements on all days. To gain insight into the extremes that could occur due to these random errors, a large number of runs was made (100) for each year.

The effect of random errors on the simulated yield was very small. The largest deviation in simulated yield found in the $34 \mathrm{yr} \times 100$ runs was only $400 \mathrm{~kg}$ $\mathrm{ha}^{-1}$. So when only random errors occur in weather data there is no need to take them into account. In practice, however, weather data are subject to systematic errors. Precipitation, for instance, is always underestimated (Buishand \& Velds 1980), and systematic errors are sometimes larger than random errors (de Vries 1955). The effects of systematic over- or underestimation of weather data on the simulation results, as discussed in the previous paragraphs, are therefore a better representation of the possible effects of irregularities in weather data on the simulation results.

\section{ALL DATA FROM ANOTHER STATION}

As for the potential production (Nonhebel 1994a), the effect of using data for all variables from another station was studied. The results are given in Fig. 16. Large deviations in simulated yield were found, even for weather data from De Bilt. In 1975 the yield was underestimated by $2 \mathrm{t} \mathrm{h.-1}$, which was due to the far 
yield $\left(10^{3} \mathrm{~kg} \mathrm{ha}^{-1}\right)$, data from other station

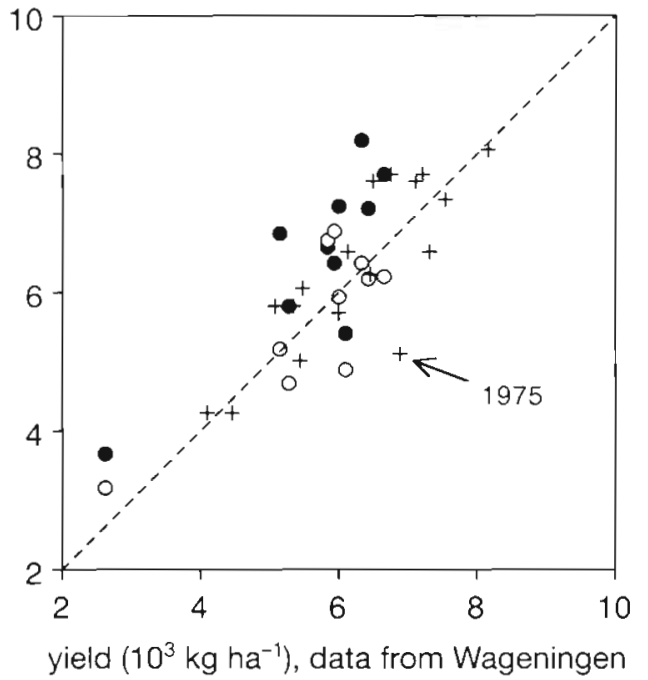

Fig. 16. Comparison between water-limited spring wheat yield simulated with the weather data from Wageningen (1961 to 1987) and the yield simulated with the complete weather data from: (0) De Bilt, 1976 to 1985; (-) De Kooy, 1976 to 1985: (+) De Bilt, 1961 to 1975 and 1986 to 1987

lower precipitation amount in De Bilt $(100 \mathrm{~mm}$ less during the growing season). When the precipitation data in the data set from De Bilt (1975) were replaced by those from Arnhem in 1975, the deviation in simulated yield was reduced to less than $1 \mathrm{th} \mathrm{h}^{-1}$ (see 'Precipitation').

\section{Conclusions}

Even when 2 sites are in the same climatic district, there will be differences in their daily weather, such that large deviations in simulated yield can occur. An important part of this deviation is caused by differences in precipitation. When no weather data from a field experiment are available for simulating waterlimited production, the best solution is to use air temperature, radiation, vapour pressure and wind speed data from a nearby weather station and rainfall data from the nearest rainfall station.

\section{GENERAL DISCUSSION}

The sensitivity of a crop growth simulation model to inaccuracies in weather data is strongly determined by the way effects of weather on crop growth are simulated. In models consisting only of linear relations, use of average values instead of daily data will not influence the simulation result.
The type of crop simulated will also affect model sensitivity. From wheat, only the production during the last weeks of the growing season is harvested. Hence overestimation of global radiation can result in a decline in yield (see 'Global Radiation'). When the total biomass of a crop is harvested this will not occur, because the overestimated production early in the season is included in the yield.

The effect of using averages and data from another station on the simulation output is dependent on the climate. In The Netherlands there is large variation in the weather conditions from one day to the next, as was shown for temperature and radiation in Nonhebel (1994a). This variation implies that an average value is not a good estimate for a daily one. In climates where weather differences between successive days are smaller, averages are likely to be better estimates for daily values, and thus the deviation in simulation results may be smaller. The effect of using averages in other climates is discussed in Nonhebel (1994b).

The Dutch climate is largely influenced by the sea. Hence there is a gradient in all weather elements from west to east over the country. Due to this gradient and the very irregular distribution of the precipitation, large differences in weather can exist over relatively small distances $(40 \mathrm{~km})$. In climates where the regional differences are smaller, the effect of using data from another station on simulation results may be smaller than found here. On the other hand, the density of meteorological stations in western Europe is the highest in the world, and use of data from another station is a realistic option. On other continents the nearest station is often too far away.

The effects of irregularities in weather data on simulation results as found here are therefore not entirely applicable to other models and other climates. Nevertheless, it was shown that inaccuracies in weather data are such that they can influence the simulation results to a large extent. Users of simulation models should be aware of them and realise that deviations between simulations and field experiments can be caused by the irregularities in weather data. It was also shown that use of average weather data as input in models developed for daily values is not without risk and that choice of the site where weather data are obtained has a large effect on the simulation results. Therefore weather data should not be considered errorless and should not be taken at face value.

Acknowledgements. This work was partly funded by the Ministry of Housing, Physical Planning and Environment (VROM) of the Dutch government and partly by the Commission of the European Communities (EV4C-0019-NL). I thank

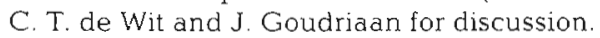




\section{LITERATURE CITED}

Buishand, T. A. Velds, C. A. (1980). Neerslag en verdamping. Klimaat van Nederland 1. KNMI (Royal Netherlands Meteorological Institute), De Bilt

de Bruin, H. A. R. (1973). Gegevens betreffende neerslag en verdamping verzameld in Salland, gedurende 1970-1972 ten behoeve van de Werkgroep Hydrologisch Onderzoek Overijssel. KNMI Wetensch. Rapport WR 73-4. KNMI (Royal Netherlands Meteorological Institute), De Bilt

de Vries, D. A. (1955). Solar radiation at Wageningen. Meded. Landbouwhogesch. Wageningen 55: 6

de Wit, C. T. (1958). Transpiration and crop yields. Agricultural Research Reports 64.6, Pudoc, Wageningen

de Zeeuw, J. W. (1963). Over de werkelijkheidsbenadering van gemeten neerslagen. Landbouwkd. Tijdschr. 75: $815-832$

Duivenvoorden, J. C. M. (1986). Inventarisatie meteostations. Klimatologische gegevens van Nederlandse stations no 26. KNMI 150-26. KNMI (Royal Netherlands Meteorological Institute), De Bilt

Geng, S., Penning de Vries, F. W. T., Supit, 1. (1986). A simple method for generating daily rainfall data. Agricult. For. Meteorol. 36: 363-376

Goudriaan, J. (1977). Crop micrometeorology: a simulation study. Simulation Monographs, Pudoc, Wageningen

Können, G. P. (1983). Het weer in Nederland. Thieme, Zutphen

Kramer, C., Post, J. J., Woudenberg, J. P. M. (1954). Precision and reliability of open-air temperature and humidity measurements with mercury thermometers. KNMI Med-

Editor: G. Esser, Gießen, Germany edelingen en verhandelingen 60. KNMI (Royal Netherlands Meteorological Institute), De Bilt

Monteith, J. L. (1965). Evaporation and environment. Proc. Symp. Soc. Exp. Biol. 19: 205-234

Nonhebel, S. (1994a). Inaccuracies in weather data and their effects on crop growth simulation results. I. Potential production. Clim. Res. 4: 47-60

Nonhebel, S. (1994b). The effect of use of average instead of daily weather data in crop growth simulation models. Agricult. Syst. 44: 377-396

Parton, W. J., Logan, J. A. (1981). A model for diurnal variation in soil and air temperature. Agric. Meteorol. 23: $205-216$

Rodda, J. C. (1971). The precipitation measurement paradox - the instrument accuracy problem. Rep. No. 16, World Meteorological Organization, Geneva

Sevruk, B. (1989). Reliability of precipitation measurement. In: Sevruk, B. (ed.) Precipitation measurement. WMO workshop on precipitation measurement, St. Moritz 3-7 Dec. 1989, Zurich, Switzerland. World Meteorological Organization, Geneva, p. 7-10

van Keulen, H., Seligman, N. G. (1987). Simulation of water use, nitrogen nutrition and growth of a spring wheat crop. Simulation Monographs, Pudoc, Wageningen

Wieringa, J., Rijkoort, P. J. (1.983). Windklimaat van Nederland. Klimaat van Nederland 2. Staatsuitgeverij, Den Haag

WMO (World Meteorological Organization) (1983). Guide to meteorological instruments and methods of observation. WMO No. 8, World Meteorological Organization, Geneva

Manuscript first received: February 17, 1993

Revised version accepted: January 7, 1994 